\title{
Should antibiotic prophylaxis after urinary catheter removal be standard practice?
}

There is an error in this Editorial by Juthani-Mehta (BMJ 2013;346:f3938, doi:10.1136/bmj.f3938). A typographical error in the linked Research paper by Jonas Marschall (BMJ 2013;346:f3147), for which a correction has already been posted, was reproduced in the Editorial. As this was cited from an unpublished source, the editorialist could not have realised it was an error. The correction regards an incorrect number in table 1 in Marschall's paper. In the 2006 study by Brandenburg et al, the median number of days of catheterisation in the control group should have read 3 (not 33, as was published in the paper). Consequently, the seventh sentence in the third paragraph of the Editorial is incorrect and should be deleted: "In addition, the median duration of catheterisation was much higher in the control group than in the antibiotics group (33 days $v 3$ days)." This error does not affect the rest of the article.

Cite this as: BMJ 2014;348:g1571

๑ BMJ Publishing Group Ltd 2014 